\title{
Response of weeds to different doses of Dragon 450 WG and Granstar Ultra SX 50 SG in spring barley
}

\author{
Skuteczność chwastobójcza obniżonych dawek preparatów \\ Dragon 450 WG i Granstar Ultra SX 50 SG w uprawie jęczmienia jarego
}

\author{
Krystyna Miklaszewska, Roman Kierzek
}

\begin{abstract}
Summary
The aim of this study was to evaluate weed susceptibility to herbicides, applied at reduced doses in spring barley. Two herbicides: Dragon 450 WG (aminopyralid + florasulam) and Granstar Ultra SX 50 SG (thifensulfuron-methyl + tribenuron-methyl) were used in a tank-mixture with the adjuvant Olstick $90 \mathrm{EC}$ at a dose of $1.0 \mathrm{l} / \mathrm{ha}$ or Trend $90 \mathrm{EC}$ at the concentration of $0.05 \%$, respectively. Each herbicide was applied in five doses: at the recommended dose, and in 75, 60, 50 and $25 \%$ of the recommended one.

The experiments were conducted over two growing seasons (2011 and 2012) at the Agricultural Experimental Station of the Institute of Plant Protection - National Research Institute in Winna Góra. The experiments were set up by randomized block design with four replications. The tested herbicides were applied at the full tillering stage of spring barley (BBCH 21-25). During treatment the weed species were at the growth stage of 2-6 true leaves. The most common species of weeds were: Chenopodium album, Viola arvensis, Anthemis arvensis, Stellaria media, Polygonum convolvulus, Veronica arvensis, Cirsium arvense and Galium aparine. The results showed the possibility to reduce the herbicide doses up to $50 \%$ while maintaining their high herbicidal effectiveness and good effect on the stability of grain yield.
\end{abstract}

Key words: spring barley, weeds, reduced doses, herbicide, adjuvant, aminopyralid + florasulam, thifensulfuron-methyl + tribenuronmethyl

\section{Streszczenie}

Celem badań była ocena wrażliwości chwastów występujących w uprawie jęczmienia jarego na obniżone dawki herbicydów Dragon 450 WG (aminopyralid + florasulam) oraz Granstar Ultra SX 50 SG (tifensulfuron metylowy + tribenuron metylowy) wprowadzonych na rynek w ostatnim czasie. Dragon 450 WG stosowano łącznie z adiuwantem Olstick 90 EC w dawce 1 l/ha. Trend 90 EC w stężeniu 0,05\% stanowił dodatek do herbicydu Granstar Ultra SX 50 SG. Każdy z testowanych środków stosowano w pięciu dawkach: w dawce zalecanej oraz w 75, 60, 50 i 25\% dawki zalecanej.

Doświadczenia prowadzono przez dwa sezony wegetacyjne (2011 i 2012) na terenie Polowej Stacji Doświadczalnej Instytutu Ochrony Roślin - Państwowego Instytutu Badawczego w Winnej Górze, w układzie bloków losowanych, w czterech powtórzeniach. Badane herbicydy aplikowano w fazie pełni krzewienia jęczmienia jarego (BBCH 21-25). W momencie zabiegu chwasty znajdowały się w fazie od 2 do 6 liści właściwych.

Najczęściej występującymi gatunkami chwastów były: Chenopodium album, Viola arvensis, Anthemis arvensis, Stellaria media, Polygonum convolvulus, Veronica arvensis, Cirsium arvense i Galium aparine.

Wyniki badań wskazują na możliwość obniżenia dawek badanych herbicydów nawet o połowę przy zachowaniu ich skuteczności chwastobójczej oraz stabilnego plonowania jęczmienia jarego.

Słowa kluczowe: jęczmień jary, chwasty, obniżone dawki, herbicyd, adiuwant, aminopyralid + florasulam, tifensulfuron-metyl + tribenuron-metyl

Instytut Ochrony Roślin - Państwowy Instytut Badawczy

Władysława Węgorka 20, 60-318 Poznań

K.Miklaszewska@iorpib.poznan.pl 


\section{Wstęp / Introduction}

Podstawą działań zapobiegawczych w ochronie jęczmienia jarego przed chwastami powinno być eliminowanie zagrożeń potencjalnego zachwaszczenia oraz stymulowanie naturalnych czynników stwarzających korzystne warunki do rozwoju. Celem tych działań jest optymalne wykorzystanie potencjału konkurencyjnego tej rośliny uprawnej (Woźnica 2008; Paradowski i wsp. 2010). Jęczmień jary mimo, że charakteryzuje się mniejszą konkurencyjnością względem chwastów w porównaniu, np. z owsem, w dogodnych warunkach siedliskowych i pogodowych silnie się krzewi i skutecznie konkuruje z chwastami o składniki pokarmowe i wodę (Buczyński i Marks 2003). W praktyce rolniczej, do tej pory najczęstszą metodą ochrony upraw przed zachwaszczeniem było stosowanie herbicydów (Haliniarz i Kapeluszny 2012). Aplikowanie dużych ilości chemicznych środków ochrony roślin wywołuje szereg negatywnych skutków, takich jak wzrost szkodliwych pozostałości w glebie i ziarnie, a także wzrost skażenia środowiska naturalnego (Domaradzki i Sadowski 2002; Krawczyk 2007). Obecnie $z$ uwagi na wysoki poziom nawożenia i uproszczenia zmianowania obniża się wskaźnik bioróżnorodności chwastów na polach uprawnych, a wzrasta zagrożenie spowodowane kompensacją niektórych gatunków (Szymankiewicz i wsp. 2003; Jędruszczak i Antoszek 2004). Podstawowym elementem zrównoważonego rolnictwa jest technologia integrowanej ochrony roślin, zakładająca między innymi aplikowanie obniżonych dawek herbicydów (Gołębiowska i Domaradzki 2010; Haliniarz i Kapeluszny 2012). W integrowanej ochronie przy podjęciu decyzji o wykonaniu zabiegu należy uwzględnić progi szkodliwości dla danego gatunku i jeżeli jest to konieczne należy wykonać zabieg odchwaszczający. $\mathrm{Na}$ podstawie badań $\mathrm{z}$ obniżonymi dawkami, wielu autorów stwierdza, że należy dążyć do ograniczenia, a nie całkowitego zniszczenia chwastów (Fisher i Davies 1993; Domaradzki i Rola 2003; Domaradzki 2006; Krawczyk 2008). Pojawiające się na rynku herbicydy $z$ nowymi substancjami czynnymi i w unowocześnionych formulacjach są rejestrowane w wąskim zakresie zalecanych dawek do skutecznego zwalczania wybranych gatunków chwastów. Brak jest informacji o poziomie wrażliwości poszczególnych gatunków na różne dawki tych środków.

Celem badań była ocena wrażliwości chwastów występujących w uprawie jęczmienia jarego na obniżone dawki herbicydów wprowadzonych na rynek w ostatnim czasie. Badania obejmowały reakcję chwastów na aminopyralid + florasulam (Dragon $450 \mathrm{WG}$ ) oraz tifensulfuron metylowy+ tribenuron metylowy (Granstar Ultra SX 50 SG), stosowane z dodatkiem adiuwantów.

\section{Materiały i metody / Materials and methods}

Doświadczenia nad stosowaniem obniżonych dawek herbicydów wraz $\mathrm{z}$ adiuwantami $\mathrm{w}$ uprawie jęczmienia jarego prowadzono przez dwa sezony wegetacyjne (2011 i 2012). Założono je na terenie Polowej Stacji Doświadczalnej Instytutu Ochrony Roślin - Państwowego Instytutu
Badawczego w Winnej Górze w układzie bloków losowanych w czterech powtórzeniach. Doświadczenia założone na glebach płowych wytworzonych z piasków gliniastych średnich wykonano na dwóch odmianach jęczmienia jarego: Rubinek (2011) oraz Antek (2012). Do badań wybrano dwa dwuskładnikowe herbicydy: Dragon 450 WG zawierający $150 \mathrm{~g} / \mathrm{kg}$ florasulamu i $300 \mathrm{~g} / \mathrm{kg}$ aminopyralidu - związków z grupy triazolpirymidyn oraz Granstar Ultra SX 50 SG zawierający jako substancje czynne związki z grupy pochodnych sulfonylomocznika$25 \%$ tifensulfuronu oraz $25 \%$ tribenuronu metylowego. Badane herbicydy aplikowano w fazie pełni krzewienia jęczmienia jarego, tzn. w fazie BBCH 21-25. W momencie zabiegu chwasty znajdowały się w fazie od 2 do 6 liści właściwych. Każdy $\mathrm{z}$ testowanych środków stosowano w pięciu dawkach: w dawce zalecanej oraz w 75, 60, 50 i 25\% dawki zalecanej. Dragon $450 \mathrm{WG}$ stosowano łącznie $\mathrm{z}$ adiuwantem Olstick $90 \mathrm{EC} \mathrm{w}$ dawce 1 1/ha. Trend $90 \mathrm{EC}$ W stężeniu $0,05 \%$ stanowił dodatek do herbicydu Granstar Ultra SX 50 SG. Obserwacje zwalczania najliczniej występujących chwastów przeprowadzono 14 i 60 dni po wykonaniu zabiegu. $\mathrm{Na} 1 \mathrm{~m}^{2}$ obiektu kontrolnego przy pomocy ramki o wymiarach $0,25 \times 1,0 \mathrm{~m}$ ustalono liczbę poszczególnych gatunków chwastów. W oparciu o te dane na każdym poletku oceniano w procentach skuteczność herbicydów (liczebność i kondycja chwastów). Ponadto na powierzchni $1 \mathrm{~m}^{2}$ określona została zielona masa poszczególnych gatunków chwastów, zarówno na obiektach kontrolnych, jak i zabiegowych. Po zbiorach ustalono wysokość plonu, masę tysiąca ziaren oraz gęstość ziarna w stanie zsypnym. Wyniki 2-letnich obserwacji uśredniono, a plon jęczmienia jarego poddano analizie statystycznej (test t-Studenta na poziomie 5\%).

\section{Wyniki i dyskusja / Results and discussion}

Chwasty wykazują wyższą wrażliwość na niższe dawki herbicydów we wcześniejszych stadiach rozwojowych (Dogan i wsp. 1999; Domaradzki i wsp. 2003; Krawczyk 2007). Zastosowane w doświadczeniach herbicydy aplikowano więc we wcześniejszych fazach rozwojowych chwastów, jednakże w zalecanych przez etykiety-instrukcje stosowania stadiach rozwojowych jęczmienia jarego (BBCH 21-25).

W trakcie dwuletnich badań w uprawie jęczmienia jarego najczęściej występującymi gatunkami chwastów były: Chenopodium album, Viola arvensis, Anthemis arvensis, Stellaria media, Polygonum convolvulus, Veronica arvensis, Cirsium arvense i Galium aparine.

Według Latowskiego (2002), Krawczyka (2007) oraz Paradowskiego i wsp. (2010) Ch. album jest gatunkiem pospolitym we wszystkich regionach Polski i najczęściej występującym w zbożach jarych. W przeprowadzonych doświadczeniach liczba sztuk komosy białej na $1 \mathrm{~m}^{2}$ była wielokrotnie wyższa od innych gatunków. Już pierwsza ocena zwalczania poszczególnych gatunków chwastów, przeprowadzona 14 dni po wykonaniu zabiegu wykazała dość wysoką skuteczność obu badanych herbicydów. Zdecydowanie lepiej w stosunku do szybkości i skuteczności działania prezentował się Granstar Ultra SX 50 SG, 
Tabela 1. Wpływ różnych dawek herbicydów na skuteczność zwalczania chwastów w jeczmieniu jarym (Winna Góra 2011-2012) Table 1. Efficacy of different doses of herbicides in spring barley (Winna Góra 2011-2012)

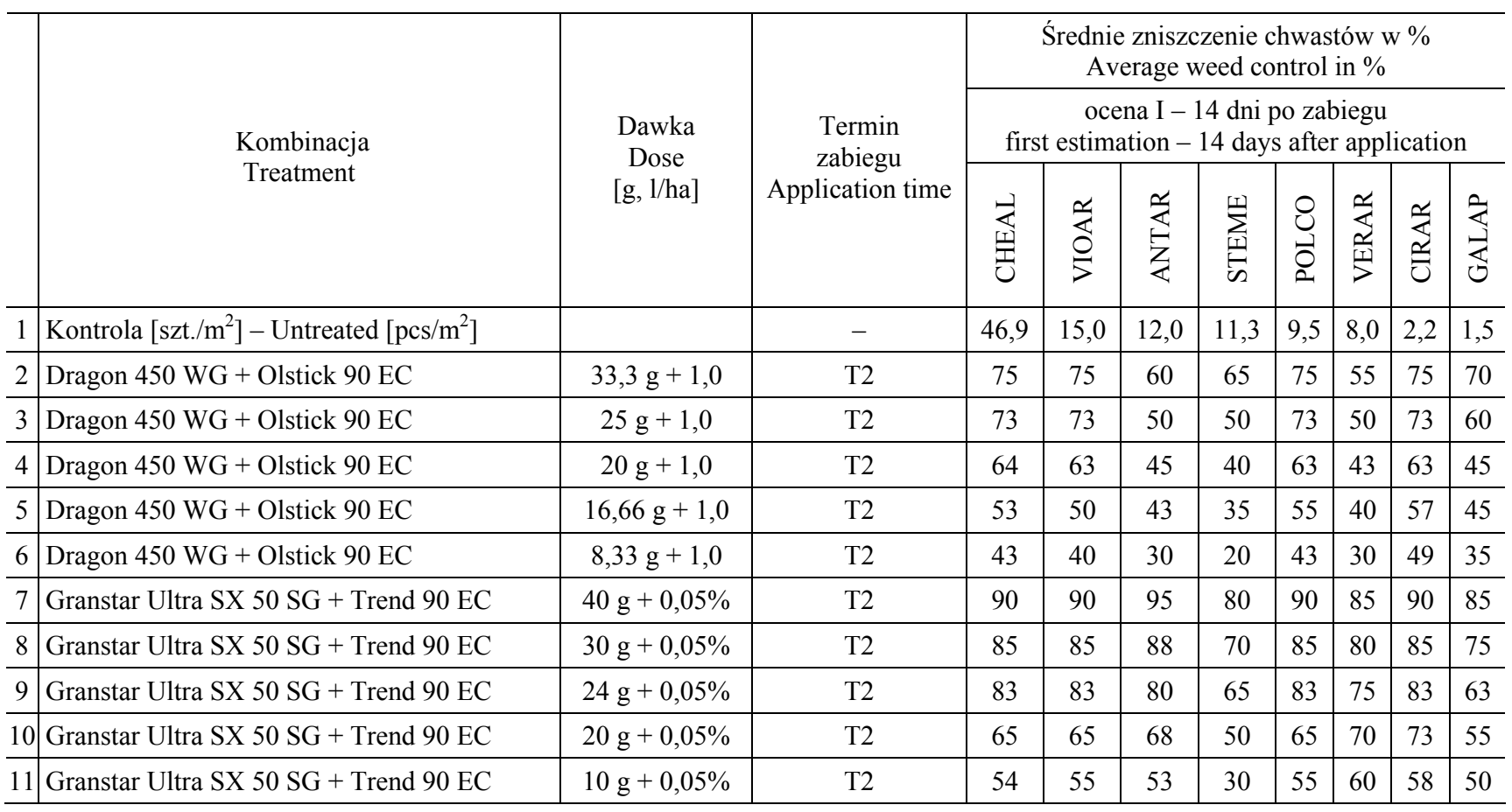

Termin zabiegu: T2 - w fazie pełni krzewienia jęczmienia jarego (BBCH 21-25)

Time of application: T2 - full tillering of spring barley (BBCH 21-25)

CHEAL - Chenopodium album, VIOAR - Viola arvensis, ANTAR - Anthemis arvensis, STEME - Stellaria media, POLCO - Polygonum convolvulus,

VERAR - Veronica arvensis, CIRAR - Cirsum arvense, GALAP - Galium aparine

Tabela 2. Wpływ różnych dawek herbicydów na skuteczność zwalczania chwastów w jeczmieniu jarym (Winna Góra 2011-2012) Table 2. Efficacy of different doses of herbicides in spring barley (Winna Góra 2011-2012)

\begin{tabular}{|c|c|c|c|c|c|c|c|c|c|c|c|}
\hline & \multirow{3}{*}{$\begin{array}{l}\text { Kombinacja } \\
\text { Treatment }\end{array}$} & \multirow{3}{*}{$\begin{array}{c}\begin{array}{c}\text { Dawka } \\
\text { Dose }\end{array} \\
\text { [g, l/ha] }\end{array}$} & \multirow{3}{*}{$\begin{array}{c}\text { Termin } \\
\text { zabiegu } \\
\text { Application time }\end{array}$} & \multicolumn{8}{|c|}{$\begin{array}{l}\text { Średnie zniszczenie chwastów w \% } \\
\text { Average weed control in \% }\end{array}$} \\
\hline & & & & \multicolumn{8}{|c|}{$\begin{array}{l}\text { ocena II }-60 \text { dni po zabiegu } \\
\text { second estimation }-60 \text { days after application }\end{array}$} \\
\hline & & & & 忘 & 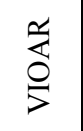 & 总 & $\sum_{\substack{|=1\\
|=1}}^{\infty}$ & $\begin{array}{l}0 \\
\substack{0 \\
0}\end{array}$ & $\underset{\frac{\alpha}{4}}{\frac{\alpha}{y}}$ & 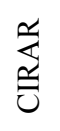 & 密 \\
\hline 1 & Kontrola $\left[\mathrm{szt} . / \mathrm{m}^{2}\right]-$ Untreated $\left[\mathrm{pcs} / \mathrm{m}^{2}\right]$ & & - & 46,9 & 15,0 & 12,0 & 11,3 & 9,5 & 8,0 & 2,2 & 1,5 \\
\hline 2 & Dragon $450 \mathrm{WG}+$ Olstick $90 \mathrm{EC}$ & $33,3 \mathrm{~g}+1,0$ & $\mathrm{~T} 2$ & 100 & 100 & 95 & 100 & 100 & 100 & 95 & 98 \\
\hline 3 & Dragon $450 \mathrm{WG}+$ Olstick $90 \mathrm{EC}$ & $25 \mathrm{~g}+1,0$ & $\mathrm{~T} 2$ & 97 & 99 & 88 & 100 & 95 & 100 & 88 & 95 \\
\hline 4 & Dragon $450 \mathrm{WG}+$ Olstick $90 \mathrm{EC}$ & $20 \mathrm{~g}+1,0$ & $\mathrm{~T} 2$ & 93 & 87 & 85 & 100 & 90 & 100 & 85 & 85 \\
\hline 5 & Dragon $450 \mathrm{WG}+$ Olstick $90 \mathrm{EC}$ & $16,66 \mathrm{~g}+1,0$ & $\mathrm{~T} 2$ & 89 & 85 & 85 & 90 & 90 & 90 & 85 & 80 \\
\hline 6 & Dragon $450 \mathrm{WG}+$ Olstick $90 \mathrm{EC}$ & $8,33 \mathrm{~g}+1,0$ & $\mathrm{~T} 2$ & 65 & 70 & 60 & 75 & 68 & 75 & 60 & 60 \\
\hline 7 & Granstar Ultra SX $50 \mathrm{SG}+$ Trend $90 \mathrm{EC}$ & $40 \mathrm{~g}+0,05 \%$ & $\mathrm{~T} 2$ & 99 & 99 & 90 & 100 & 98 & 100 & 90 & 100 \\
\hline 8 & Granstar Ultra SX $50 \mathrm{SG}+$ Trend $90 \mathrm{EC}$ & $30 \mathrm{~g}+0,05 \%$ & $\mathrm{~T} 2$ & 95 & 100 & 90 & 100 & 95 & 100 & 90 & 100 \\
\hline 9 & Granstar Ultra SX $50 \mathrm{SG}+$ Trend $90 \mathrm{EC}$ & $24 \mathrm{~g}+0,05 \%$ & $\mathrm{~T} 2$ & 95 & 100 & 80 & 100 & 90 & 100 & 80 & 95 \\
\hline 10 & Granstar Ultra SX $50 \mathrm{SG}+$ Trend $90 \mathrm{EC}$ & $20 \mathrm{~g}+0,05 \%$ & $\mathrm{~T} 2$ & 93 & 90 & 75 & 95 & 88 & 95 & 75 & 95 \\
\hline 11 & Granstar Ultra SX $50 \mathrm{SG}+$ Trend 90 EC & $10 \mathrm{~g}+0,05 \%$ & $\mathrm{~T} 2$ & 68 & 70 & 50 & 75 & 80 & 75 & 50 & 85 \\
\hline
\end{tabular}

Termin zabiegu: T2 - w fazie pełni krzewienia jęczmienia jarego (BBCH 21-25)

Time of application: T2 - full tillering of spring barley (BBCH 21-25)

CHEAL - Chenopodium album, VIOAR - Viola arvensis, ANTAR - Anthemis arvensis, STEME - Stellaria media, POLCO - Polygonum convolvulus,

VERAR - Veronica arvensis, CIRAR - Cirsum arvense, GALAP - Galium aparine 
Tabela 3. Wpływ zróżnicowanych dawek herbicydów na zieloną masę chwastów (Winna Góra 2011-2012)

Table 3. The effect of different doses of herbicides on fresh weed weight (Winna Góra 2011-2012)

\begin{tabular}{|c|c|c|c|c|c|c|c|c|c|c|}
\hline & \multirow{3}{*}{$\begin{array}{l}\text { Kombinacja } \\
\text { Treatment }\end{array}$} & \multirow{3}{*}{$\begin{array}{c}\text { Dawka } \\
\text { Dose } \\
{[\mathrm{g}, \mathrm{l} / \mathrm{ha}]}\end{array}$} & \multirow{3}{*}{$\begin{array}{c}\text { Termin } \\
\text { zabiegu } \\
\text { Application } \\
\text { time }\end{array}$} & \multicolumn{7}{|c|}{$\begin{array}{l}\text { Średnia waga chwastów [g] } \\
\text { Average weed biomass }[\mathrm{g}]\end{array}$} \\
\hline & & & & \multicolumn{7}{|c|}{$\begin{array}{l}\text { ocena II }-6 \text { tygodni po zabiegu } \\
\text { second estimation }-6 \text { weeks after application }\end{array}$} \\
\hline & & & & 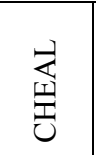 & 恋 & 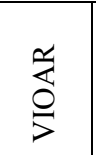 & 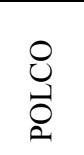 & $\sum_{\substack{\mid=1 \\
\qquad}}^{\underbrace{}_{\infty}}$ & 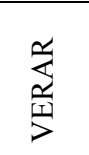 & 悹 \\
\hline 1 & Kontrola $\left[\mathrm{szt} . / \mathrm{m}^{2}\right]-$ Untreated $\left[\mathrm{pcs} / \mathrm{m}^{2}\right]$ & & - & 199,9 & 20,3 & 14,3 & 9,8 & 2,3 & 1,8 & 0,4 \\
\hline 2 & Dragon $450 \mathrm{WG}+$ Olstick $90 \mathrm{EC}$ & $33,3 \mathrm{~g}+1,0$ & $\mathrm{~T} 2$ & 11,1 & 0,4 & 0,5 & 0,0 & 0,0 & 0,0 & 0,0 \\
\hline 3 & Dragon $450 \mathrm{WG}+$ Olstick $90 \mathrm{EC}$ & $25 \mathrm{~g}+1,0$ & $\mathrm{~T} 2$ & 12,0 & 1,7 & 1,7 & 0,1 & 0,0 & 0,1 & 0,1 \\
\hline 4 & Dragon $450 \mathrm{WG}+$ Olstick $90 \mathrm{EC}$ & $20 \mathrm{~g}+1,0$ & $\mathrm{~T} 2$ & 12,5 & 3,4 & 3,5 & 0,3 & 0,0 & 4,4 & 0,3 \\
\hline 5 & Dragon $450 \mathrm{WG}+$ Olstick $90 \mathrm{EC}$ & $16,66 \mathrm{~g}+1,0$ & $\mathrm{~T} 2$ & 17,6 & 6,2 & 3,7 & 0,5 & 0,0 & 9,5 & 0,4 \\
\hline 6 & Dragon $450 \mathrm{WG}+$ Olstick $90 \mathrm{EC}$ & $8,33 \mathrm{~g}+1,0$ & $\mathrm{~T} 2$ & 49,6 & 6,6 & 6,8 & 1,4 & 0,1 & 13,4 & 0,4 \\
\hline 7 & Granstar Ultra SX 50 SG + Trend 90 EC & $40 \mathrm{~g}+0,05 \%$ & $\mathrm{~T} 2$ & 0,6 & 4,9 & 7,1 & 6,0 & 0,0 & 0,8 & 0,0 \\
\hline 8 & Granstar Ultra SX 50 SG + Trend 90 EC & $30 \mathrm{~g}+0,05 \%$ & $\mathrm{~T} 2$ & 0,6 & 8,7 & 9,2 & 7,0 & 0,0 & 0,8 & 1,1 \\
\hline 9 & Granstar Ultra SX 50 SG + Trend 90 EC & $24 \mathrm{~g}+0,05 \%$ & $\mathrm{~T} 2$ & 1,1 & 18,6 & 13,2 & 7,2 & 0,0 & 5,9 & 2,7 \\
\hline 10 & Granstar Ultra SX 50 SG + Trend 90 EC & $20 \mathrm{~g}+0,05 \%$ & $\mathrm{~T} 2$ & 1,2 & 27,0 & 13,3 & 7,4 & 0,4 & 6,9 & 3,7 \\
\hline \multirow[t]{2}{*}{11} & Granstar Ultra SX 50 SG + Trend 90 EC & $10 \mathrm{~g}+0,05 \%$ & $\mathrm{~T} 2$ & 6,3 & 38,9 & 14,5 & 12,3 & 0,8 & 8,2 & 5,2 \\
\hline & $\operatorname{NIR}(0,05)-\operatorname{LSD}(0.05)$ & & & 8,722 & 9,490 & 2,765 & 1,640 & 0,253 & 3,060 & 1,065 \\
\hline
\end{tabular}

Termin zabiegu: T2 - w fazie pełni krzewienia jęczmienia jarego (BBCH 21-25)

Time of application: T2 - full tillering of spring barley (BBCH 21-25)

CHEAL - Chenopodium album, VIOAR - Viola arvensis, ANTAR - Anthemis arvensis, STEME - Stellaria media, POLCO - Polygonum convolvulus,

VERAR - Veronica arvensis, CIRAR - Cirsum arvense, GALAP - Galium aparine

Tabela 4. Wpływ zróżnicowanych dawek herbicydów na plon jęczmienia jarego (Winna Góra 2011-2012)

Table 4. The influence of various doses of herbicides on the yield of spring barley (Winna Góra 2011-2012)

\begin{tabular}{c|l|c|c|c|c|c}
\hline \multicolumn{1}{|c|}{$\begin{array}{c}\text { Kombinacja } \\
\text { Treatment }\end{array}$} & $\begin{array}{c}\text { Dawka } \\
\text { Dose } \\
{[\mathrm{g}, 1 / \mathrm{ha}]}\end{array}$ & $\begin{array}{c}\text { Termin } \\
\text { zabiegu } \\
\text { Application } \\
\text { time }\end{array}$ & $\begin{array}{c}\text { MTZ } \\
\text { Weight } \\
\text { of 1000 grains } \\
{[\mathrm{g}]}\end{array}$ & $\begin{array}{c}\text { Gestość ziarna } \\
\text { Grain density } \\
{[\mathrm{kg} / \mathrm{hl}]}\end{array}$ & $\begin{array}{c}\text { Plon } \\
\text { Yield } \\
{[\mathrm{t} / \mathrm{ha}]}\end{array}$ \\
\hline 1 & Kontrola [szt./m - Untreated [pcs $\left./ \mathrm{m}^{2}\right]$ & & - & 54,69 & 66,81 & 5,51 \\
\hline 2 & Dragon 450 WG + Olstick 90 EC & $33,3 \mathrm{~g}+1,0$ & $\mathrm{~T} 2$ & 53,68 & 66,95 & 5,68 \\
\hline 3 & Dragon 450 WG + Olstick 90 EC & $25 \mathrm{~g}+1,0$ & $\mathrm{~T} 2$ & 52,14 & 67,37 & 5,78 \\
\hline 4 & Dragon 450 WG + Olstick 90 EC & $20 \mathrm{~g}+1,0$ & $\mathrm{~T} 2$ & 54,22 & 67,37 & 5,79 \\
\hline 5 & Dragon 450 WG + Olstick 90 EC & $16,66 \mathrm{~g}+1,0$ & $\mathrm{~T} 2$ & 53,21 & 67,31 & 5,65 \\
\hline 6 & Dragon 450 WG + Olstick 90 EC & $8,33 \mathrm{~g}+1,0$ & $\mathrm{~T} 2$ & 58,88 & 66,87 & 5,77 \\
\hline 7 & Granstar Ultra SX 50 SG + Trend 90 EC & $40 \mathrm{~g}+0,05 \%$ & $\mathrm{~T} 2$ & 53,51 & 66,97 & 5,88 \\
\hline 8 & Granstar Ultra SX 50 SG + Trend 90 EC & $30 \mathrm{~g}+0,05 \%$ & $\mathrm{~T} 2$ & 53,39 & 65,86 & 5,59 \\
\hline 9 & Granstar Ultra SX 50 SG + Trend 90 EC & $24 \mathrm{~g}+0,05 \%$ & $\mathrm{~T} 2$ & 52,43 & 66,94 & 5,74 \\
\hline 10 & Granstar Ultra SX 50 SG + Trend 90 EC & $20 \mathrm{~g}+0,05 \%$ & $\mathrm{~T} 2$ & 53,18 & 66,59 & 5,94 \\
\hline 11 & Granstar Ultra SX 50 SG + Trend 90 EC & $10 \mathrm{~g}+0,05 \%$ & $\mathrm{~T} 2$ & 53,13 & 67,48 & 5,77 \\
\hline & NIR (0,05) - LSD (0.05) & & & 2,456 & 2,890 & 0,290 \\
\hline
\end{tabular}

Termin zabiegu: T2 - w fazie pełni krzewienia jęczmienia jarego (BBCH 21-25)

Time of application: T2 - full tillering of spring barley (BBCH 21-25)

którego dawka obniżona nawet do $60 \%$ zalecanej zwalczała w stopniu zadowalającym większość gatunków.

Druga ocena zniszczenia poszczególnych gatunków chwastów przeprowadzona 60 dni po zabiegu pokazała wyraźnie, iż dawki herbicydów obniżone nawet o 50\% są bardzo skuteczne. Gatunkami najlepiej zwalczanymi przez Dragon 450 WG zastosowany wraz z adiuwantem Olstick 90 EC były $S$. media, $P$. convolvulus i $V$. arvensis. 
W przypadku Granstar Ultra SX 50 SG + Trend 90 EC były to $S$. media, $V$. arvensis i $G$. aparine. Należy podkreślić, że procent zniszczenia chwastów przez oba herbicydy w dawkach obniżonych nawet o 50\% mieścił się w granicach od 80 do $100 \%$. Tylko A. arvensis oraz C. arvense traktowane $50 \%$ dawką Granstar Ultra SX $50 \mathrm{SG}$ zwalczone zostały w 75\%. Oba herbicydy stosowane $\mathrm{w}$ dawce obniżonej do $25 \%$ dawki zalecanej zwalczały chwasty w granicach od 50 do $75 \%$. Jedynie $P$. convolvulus i $G$. aparine zwalczane były w wyższym procencie (odpowiednio: 80 i 85\%) przez Granstar Ultra SX 50 SG + Trend 90 EC aplikowany w 25\% dawki zalecanej. Wykonana $\mathrm{w}$ tym samym czasie (60 dni po zabiegu) analiza zielonej masy poszczególnych gatunków chwastów potwierdziła wysoką skuteczność przeprowadzonych zabiegów i możliwość obniżenia zalecanej dawki nawet o 50\% pod warunkiem zastosowania herbicydów łącznie $\mathrm{z}$ adiuwantami.

Średni plon ziarna jęczmienia jarego kształtował się w granicach od 5,51 do 5,94 t/ha. Najniższy plon otrzymano z poletek kontrolnych. Plony uzyskane $\mathrm{z}$ obiektów traktowanych różnymi dawkami herbicydów były istotnie wyższe od plonu kontrolnego, natomiast nie różniły się istotnie pomiędzy sobą.

Analizując plony $\mathrm{z}$ poszczególnych kombinacji nie stwierdzono korelacji pomiędzy ich wysokością a poziomem zachwaszczenia.
Badania prowadzone przez innych autorów (Domaradzki i Rola 2000; Pietryga i Drzewiecki 2007; Krawczyk i Kaczmarek 2009; Paradowski i wsp. 2010) potwierdzają korzystny wpływ stosowania obniżonych dawek, w szczególności herbicydów wieloskładnikowych na skuteczne zabezpieczenie zbóż przed chwastami oraz na stabilność i wielkość uzyskiwanych plonów.

\section{Wnioski / Conclusions}

1. Stosowanie obniżonych dawek herbicydów Dragon 450 WG oraz Granstar Ultra SX 50 SG nawet do 50\% dawki zalecanej na chwasty w młodszych stadiach rozwojowych pozwoliło skutecznie zabezpieczyć uprawę jęczmienia jarego przed zachwaszczeniem.

2. Stosowanie dodatku właściwych adiuwantów jest ważnym elementem obniżania zużycia herbicydów, a także utrzymania lub poprawy efektu chwastobójczego.

3. Ograniczenie konkurencyjnego oddziaływania chwastów dwuliściennych poprzez stosowanie różnych dawek herbicydów Dragon 450 WG oraz Granstar Ultra SX 50 SG zapewniło stabilne plonowanie jęczmienia jarego.

4. Nie stwierdzono istotnych różnic w plonie ziarna i w parametrach jakościowych plonu pomiędzy kombinacjami traktowanymi herbicydami w różnych dawkach.

\section{Literatura / References}

Buczyński G., Marks M. 2003. Zachwaszczenie i plonowanie jęczmienia w płodozmianie i w monokulturze. Zesz. Probl. Post. Nauk Rol. 490: 41-47.

Dogan N.M., Kemmer A., Hurle K. 1999. Influence of weed growth stage on the performance of reduced herbicide doses. p. 165. Proc. of eleventh European Weed Research Society Symposium. Basel, 28.06-1.07.1999, 222 pp.

Domaradzki K., Rola H. 2000. Efektywność stosowania niższych dawek herbicydów w zbożach. Pam. Puł. 120: 53-64.

Domaradzki K., Sadowski J. 2002. Możliwość zmniejszenia obciążenia dla środowiska naturalnego poprzez stosowanie herbicydów w ograniczonych dawkach. Pam. Puł. 130: 99-114.

Domaradzki K., Rola H. 2003. The possibility of weed control in cereals by use low rates of herbicides - review of existing investigations. J. Plant Prot. Res. 43 (2): 163-170.

Domaradzki K., Kieloch R., Rola H. 2003. Skuteczność herbicydów w zależności od dawki i fazy rozwojowej chwastów. Prog. Plant Prot./Post. Ochr. Roślin 43 (1): 109-114.

Domaradzki K. 2006. Efektywność regulacji zachwaszczenia zbóż w aspekcie ograniczenia dawek herbicydów oraz wybranych czynników agroekologicznych. Monografie i Rozprawy Naukowe. IUNG - PIB, Puławy 17: 54-64.

Fisher N.M., Davies D.H.K. 1993. Reliability of broad-leaved weed control in cereals using low doses of herbicide. The BCPC Conference - Weeds: 1223-1228.

Gołębiowska H., Domaradzki K. 2010. Systemy chemicznej regulacji zachwaszczenia upraw rolniczych w aspekcie rolnictwa zrównoważonego. Fragm. Agron. 27 (1): 32-43.

Haliniarz M., Kapeluszny J. 2012. Reakcja trzech odmian pszenicy jarej na zmniejszenie zalecanej dawki herbicydu Chwastom Trio 540 SL. Fragm. Agron. 29 (2): 33-42.

Jędruszczak M., Antoszek R. 2004. Sposoby uprawy roli a bioróżnorodność zbiorowisk chwastów w monokulturze pszenicy ozimej. Acta Sci. Pol., Agricultura 3 (2): 47-59.

Krawczyk R. 2007. Wpływ terminu stosowania zredukowanych dawek herbicydów w zbożach jarych na efektywność zwalczania chwastów. Prog. Plant Prot./Post. Ochr. Roślin 47 (3): 151-158.

Krawczyk R. 2008. Obniżona dawka herbicydu - uwarunkowania, badania, praktyka. Prog. Plant Prot./Post. Ochr. Roślin 48 (2): $621-627$.

Krawczyk R., Kaczmarek S. 2009. Possibilities of weed control in spring cereals using small herbicide doses in Poland conditions. J. Centr. Europ. Agric. 10: 433-438.

Latowski K. 2002. Problem pospolitych chwastów segetalnych Polski. Prog. Plant Prot./Post. Ochr. Roślin 42 (1): 392-399.

Paradowski A., Pietryga J., Matysiak K. 2010. Optymalizacja dawek w pszenicy jarej i jęczmieniu jarym. Prog. Plant Prot./Post. Ochr. Roślin 50 (4): 1859-1868.

Pietryga J., Drzewiecki S. 2007. Redukcja dawek herbicydów w warunkach zróżnicowanego nawożenia azotowego a wysokość i jakość plonowania pszenicy jarej. Prog. Plant Prot./Post. Ochr. Roślin 47 (3): 234-237.

Szymankiewicz K., Jankowska D., Deryło S. 2003. Wpływ płodozmianu i monokultury oraz sposobu uprawy roli na bioróżnorodność flory zachwaszczającej pszenżyto ozime. Acta Agrophys. 1 (4): 767-772.

Woźnica Z. 2008. Herbologia. Podstawy Biologii, Ekologii i Zwalczania Chwastów. PWRiL, Poznań, 430 ss. 